TITLE:

\title{
OBSERVATION ON PSOLUS SQUAMATUS (KOREN) FROM THE OKHOTSK SEA (DENDROCHIROTA : PSOLIDAE)
}

$\operatorname{AUTHOR(S):~}$

Imaoka, Tohru

\section{CITATION:}

Imaoka, Tohru. OBSERVATION ON PSOLUS SQUAMATUS (KOREN) FROM THE OKHOTSK SEA (DENDROCHIROTA : PSOLIDAE). PUBLICATIONS OF THE SETO MARINE BIOLOGICAL LABORATORY 1980, 25(5-6): 361-372

\section{ISSUE DATE:}

1980-11-15

URL:

http://hdl.handle.net/2433/176003

RIGHT: 


\title{
OBSERVATION ON PSOLUS SQUAMATUS (KOREN) FROM THE OKHOTSK SEA (DENDROCHIROTA:PSOLIDAE) ${ }^{1)}$
}

\author{
TOHRU IMAOKA \\ Seto Marine Biological Laboratory
}

With Text-figures $1-9$

Recently, the author had a chance of making some close observations on two specimens of Psolus collected from the Okhotsk Sea off the northeastern coast of Hokkaido Island, Japan. These specimens were easily identified with $P$. squamatus (Koren) on their general morphology. This is a well-known species found rather commonly in the seas of higher latitudes in both hemispheres. Therefore, little doubts remained about this identifications at first. However, the feature of ossicles seems to differ somewhat significantly between these two specimens, and these differences remind the author of two type of the species, mentioned in detail by Ekman (1923 and 1925). Moreover, some features of ossicles in the present specimens seem to be out of the trends supposed by previous researchers on this species. Thus, it seems to the author that the present only two specimens might give a clue to make clear the morphological range of this species, and this has made the author repeat the morphological descriptions of the specimens, in the present paper, but always keeping the two types of the species and the morphological trends so far proposed by previous researchers in his mind.

Prior to enter the description, the author wishes to express his hearty thanks to $\mathrm{Mr}$. Goro Osagawa for his generosity in submitting the specimens to the author's examination and to the Seto Marine Biological Laboratory for every facility in carrying on his studies. Further, the author's gratitudes are due to Dr. Takasi Tokioka for his kindness in reading the manuscript.

\section{Psolus squamatus (Koren, 1844)}

(Figs. 1-9)

Cuvieria squamata: Koren 1844, p. 211, pls. 2-3; Selenka 1867, p. 343.

Psolus squamatus: Mitsukuri 1912, pp. 225-227, text-fig. 42; Ohshima 1915, p. 280; 1918, pp. 1-4, text-fig. 85; Ekman 1923, pp. 1-59, 37 text-gfis; Pawson 1960, p. 129.

Psolus squamatus var. segregatus: Ekaman 1925, p. 136, text-fig. 33; Deichmann 1941, p. 147, pl. 30, fig. $7 ; 1947$, p. 340.

Psolus asper: Augustin 1908, pp. 33-34, fig. 20.

1) Contributions from the Seto Marine Biological Laboratory, No. 662.

Publ. Seto Mar. Biol. Lab., XXV(5/6), 361-372, $1980 . \quad$ (Article 24) 


\section{Materials:}

Two, $41 \mathrm{~mm}$ and $54 \mathrm{~mm}$ long, of the specimens found attached to the shell of Buccinum kinukatsugi Habe \& Ito, B. osagawai Habe \& Ito and B. aniwanum Dall, all fished by shell baskets from off Rausu on the northesatern coast of Hokkaido Island, 360-630 $\mathrm{m}$ deep; dried and then preserved in alcohol.

General Morphology:

The smaller specimen, $41 \mathrm{~mm}$ long, $22 \mathrm{~mm}$ broad and $12 \mathrm{~mm}$ high, seems to retain its natural external appearance, but in the larger one, $54 \mathrm{~mm}$ long, $17 \mathrm{~mm}$ broad and $16 \mathrm{~mm}$ high, the dorsal scaled surface is slightly bent ventrally evenly but strongly laterally. The calcified scales covering the dorsal surface of the animal are white and granulated. In the smaller specimen, there are appreximately 17 scales between the mouth and the anus, 12 between the mouth and the anterior margin of the scaled dorsal surface, 16 between the anus and the posterior margin of

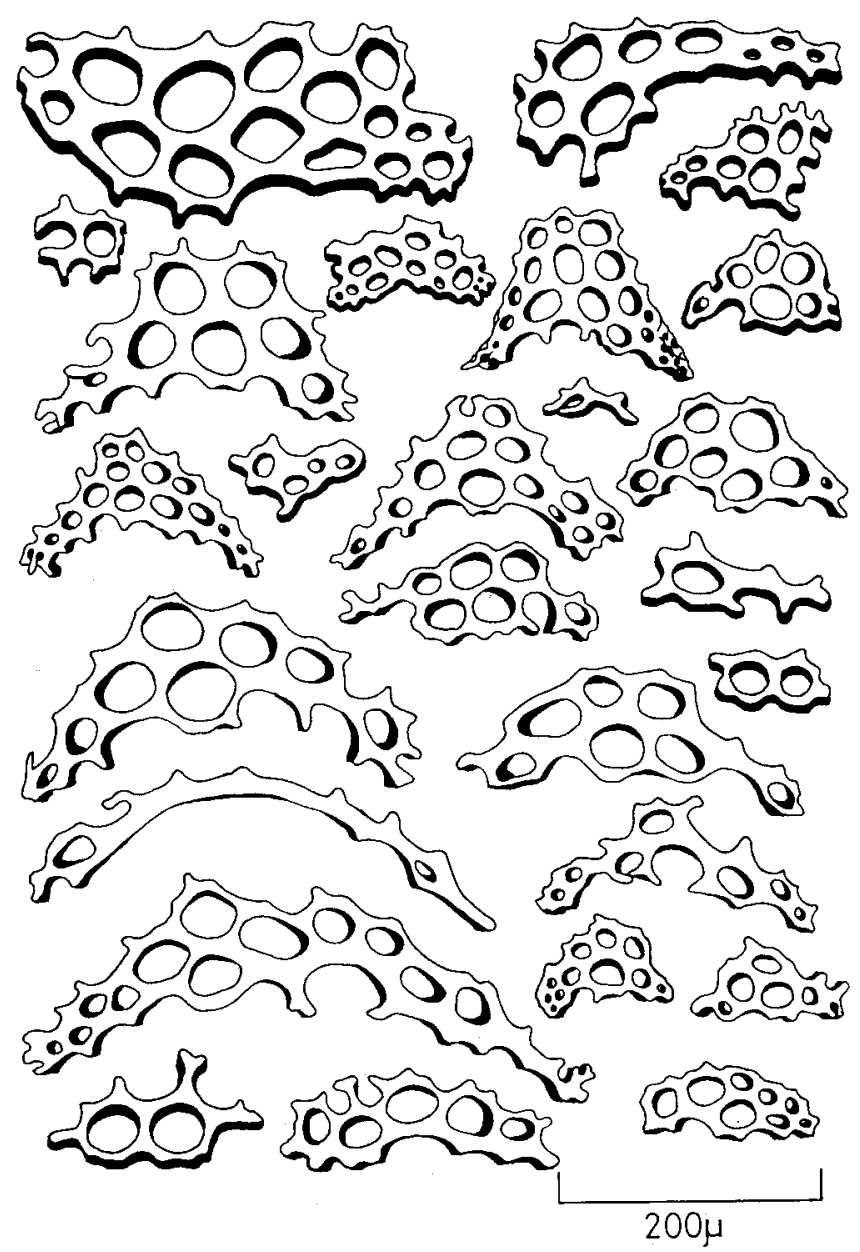

Fig. 1. Ossicles from the distal part of the tentacles of the larger specimen. 
the same surface, and 38 at the maximum between both lateral margins. In the larger specimen, there are about 20 between the mouth and the anus, 11 between the mouth and the anterior margin of the scaled dorsal surface, 12 between the anus and the posterior margin of the same surface, and 36 at the maximum between both lateral margins.

The mouth and the anus are situated respectively near the anterior and posterior edges of the animal. In the larger specimen, two larger pentagonal lateral plates are distinguishable on each side of the peristome, while in the smaller specimen no such differentiation is seen among the scales of the peristome. In the periproct, the scales become smaller distally, and in the main part of the dorsal scaled surface other than the peristome and the periproct the scales diminish the size from the central part to the periphery. The largest scale is about $6 \mathrm{~mm}$ in diameter in the smaller specimen and about $9 \mathrm{~mm}$ in the larger specimen, while the smallest one is less than $1 \mathrm{~mm}$ in diameter in both specimens.

The granules on the scale are hemispherical in each specimen. They are 240 $290 \mu$ (the mean $270 \mu), 200-280 \mu(250 \mu), 170-220 \mu(198 \mu), 180-250 \mu(207 \mu)$, $180-250 \mu(215 \mu)$ and $160-280 \mu(216 \mu)$ in diameter respectively on lateral scales, dorsal, anterior, posterior, peristomatal and periproctal scales in the smaller specimen; and in the same way 260-350 $\mu(309 \mu), 240-350 \mu(307 \mu), 190-300 \mu(237 \mu)$, $190-340 \mu(265 \mu), 190-300 \mu(250 \mu)$ and $190-290 \mu(232 \mu)$ in the larger specimen.

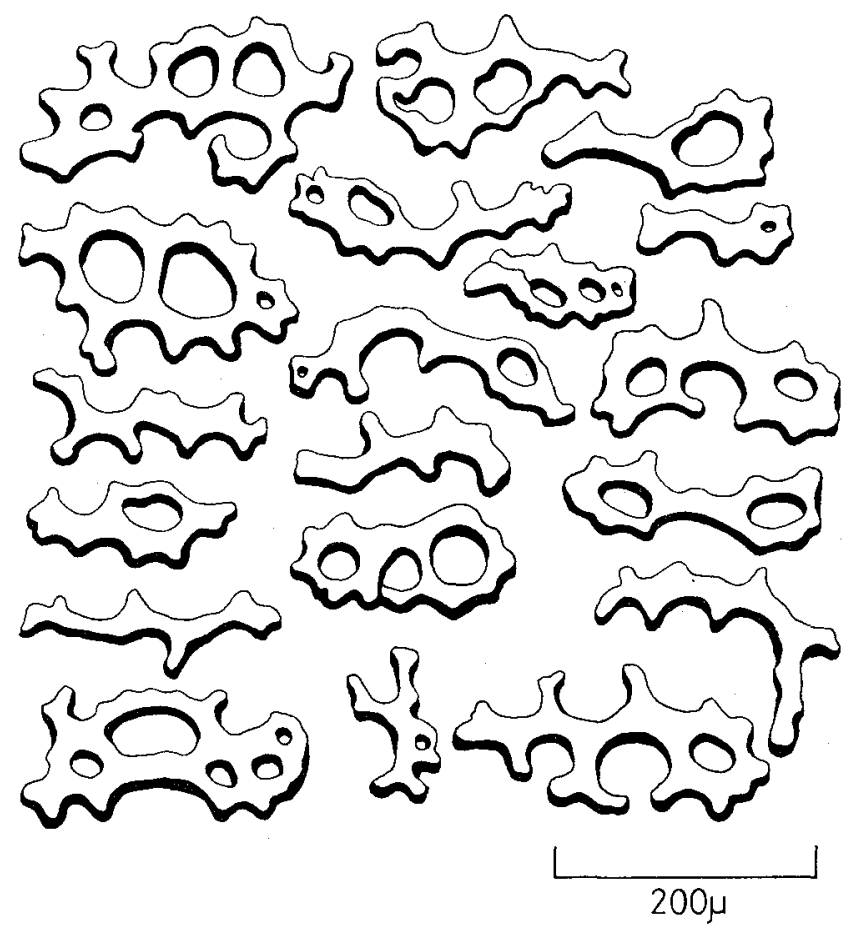

Fig. 2. Ossicles from a mid-ventral tube foot from the smaller specimen. 
The granules are larger in the larger specimen than in the smaller one, and on the lateral and dorsal scales than on the other scales in each specimen.

The tentacles are 10, all wholly retracted and neary of the same size, coloured white in the smaller but faintly reddish in the larger specimen. They are dendroid and devoid on free tentacular ampulla. The stone canal and the Polian vesicle are single respectively. The genital tube and the respiratory tree are each paired. There are five retractor muscles; anteriorly attached to the body wall just anterior to the frontal margin of the calcareous ring, but posteriorly ending attached to the longitudinal muscle in the posterior part of the body in the dorsal pair, in the middle part of the body in the ventro-lateral pair, and just posterior to the calcareous ring in the midventral retractor.

The tube feet are confined to the mid-ventral and ventrolateral ambulacra; they may reach to $1.5 \mathrm{~mm}$ in terminal diameter in larger ones and all are strongly contracted. In the midventral ambulacrum, they are found arranged in double rows in the anterior and posterior parts of the body; in the middle part only the left one of the double rows is discriminated in the smaller specimen while none of

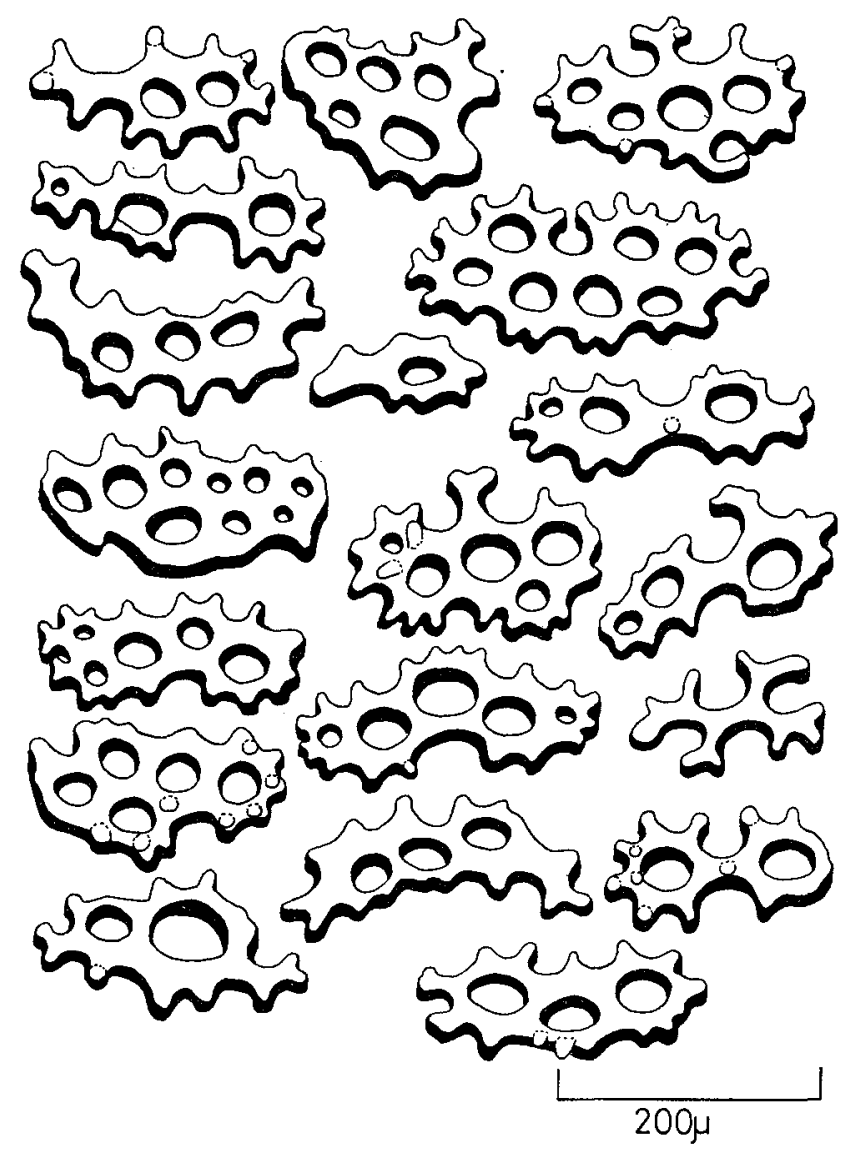

Fig. 3. Ossicles from a mid-ventral tube foot from the larger specimen. 
the tube feet can be found there in the larger specimen. In the smaller specimen, the tube feet are found somewhat crowded in the anterior and posterior parts of the right row.

In the ventro-lateral ambulacra, the tube feet are arranged on each body side in a single row along the outer ambulacrum but rather irregularly along the inner ambulacrum, namely in double rows in the anterior and posterior parts but in a single zigzag row in the middle part. They are 50 and 59 on the right and 48 and 58 on the left body side respectively along the outer and inner ambulacra in the smaller specimen, while in the same way 41 (partly defective) and 43 on the right and 51 and 43 on the left side in the larger specimen. These numbers of the tube feet given above are not always accurate, because the exact sites of the feet are somewhat confused between the rows and ambulacra near the anterior and posterior ends of the body. Further, the lateral inflection of the dorsal scales surface makes the exact counting of feet somewhat difficult, especially in the larger specimen.

Ossicles:

The ossicles can be seen in the ventral tegument, tentacles and the tube feet and around the mouth in the form of perforated plates. The ossicular plates in the tentacle, become larger from the end to the base of each tentacle, 110-780 $\mu$ long near the base, while $90-430 \mu$ near the distal end; they are somewhat triangular, slightly

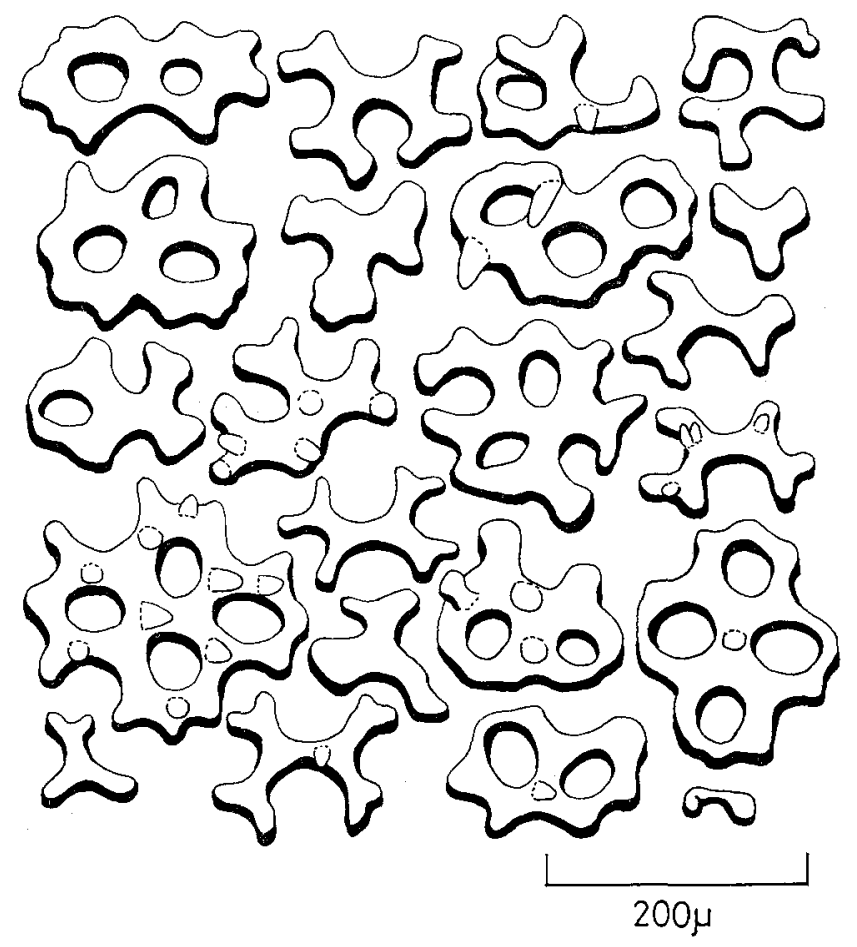

Fig. 4. Round plates from the central part of the ventral tegument of the smaller specimen. 
bent, and mostly fenestrated with a few to about a twenty holes, but devoid of any protuberances (Fig. 1). The ossicles in the tube feet are represented by the pseudobuttons that are 120-260 $\mu$ (the mean $188 \mu$ ) and 110-260 $\mu(203 \mu$ ) in length in the mid-ventral and the ventro-lateral ambulacra respectively in the smaller specimen (Fig. 2), while 140-280 $\mu(204 \mu)$ and $90-320 \mu(192 \mu)$ in the mid-ventral and the ventro-lateral ambulacra respectively in the larger specimen (Fig. 3). There is a single terminal plate in each foot, about $500 \mu$ in diameter. The number of holes is significantly larger in the larger specimen than in the smaller one. A few to several protuberances are seen on some foot ossicles from the larger specimen, but generally no protuberances are found on ossicles from the smaller specimen. However, no clear difference is seen in the ossicle length between the larger and smaller specimens. Clear difference is not seen either in numbers of holes and protuberances

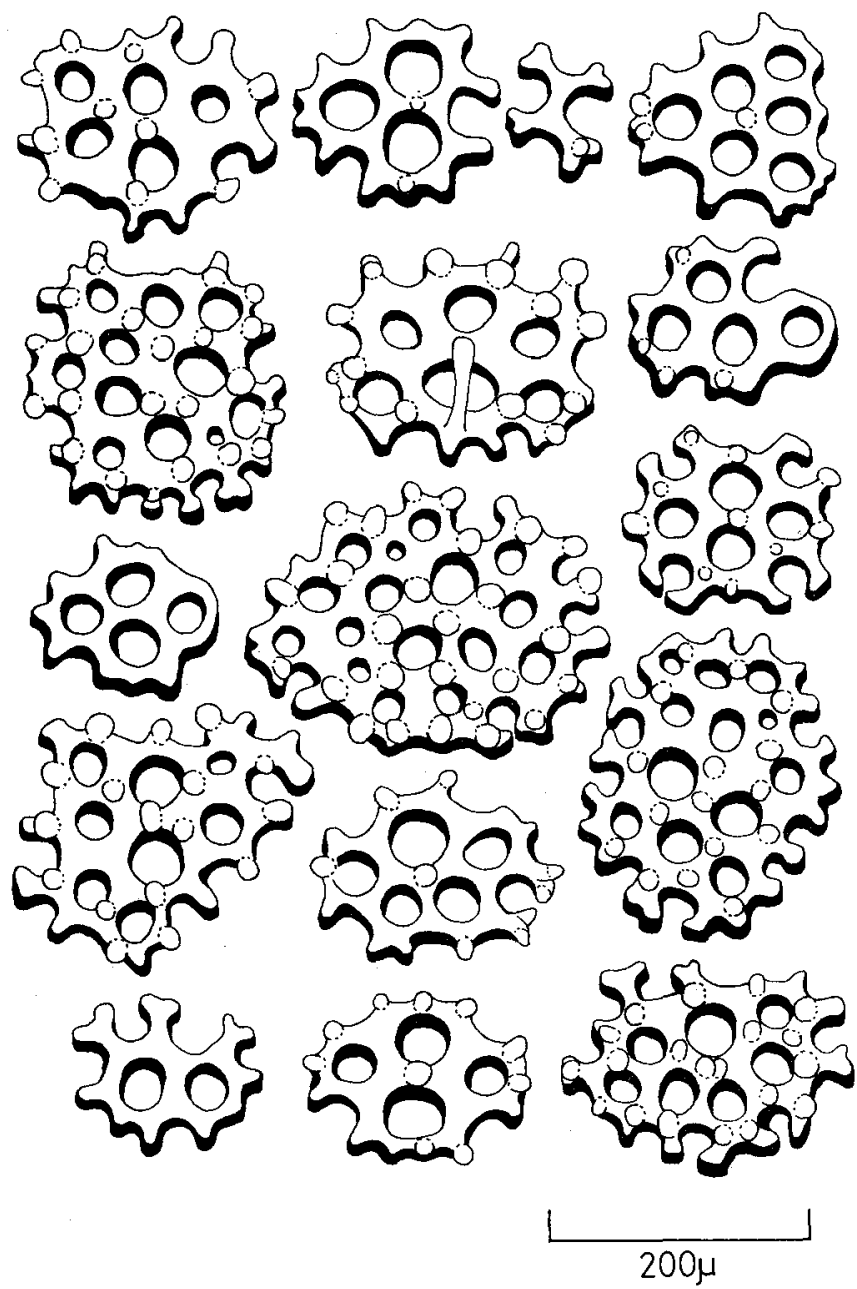

Fig. 5. Round plates from the central part of the ventral tegument of the larger specimen. 
between the tube feet from different parts of the body in each of these two specimens. The fenestrated plates in the ventral tegument are round or elongate and each furnished with many protuberances along the periphery and on the surface; though some plates may bear only a few of them. In the smaller specimen, the ossicles are distributed unevently, more densely in the marginal area than in the central part. The round plates from the central part are 70-220 $\mu$ (the mean $143 \mu$ ) (Fig. 4) and $100-270 \mu(190 \mu)$ (Fig. 5) in diameter and those from the marginal area are 140$200 \mu(170 \mu)($ Fig. 6) and 120-240 $\mu(155 \mu)$ (Fig. 7) in the smaller and larger specimens respectively. The elongated plates are $160-260 \mu(220 \mu)$ (Fig. 6) and $120-260 \mu(211 \mu)$ (Fig. 7) in length in the smaller and larger specimens respectively. Any clear difference is not seen in diameter nor in length of ossicles between these specimens. The holes in the round plates, however, are larger in the central area than in the marginal area in each specimen, and in the smaller specimen than in

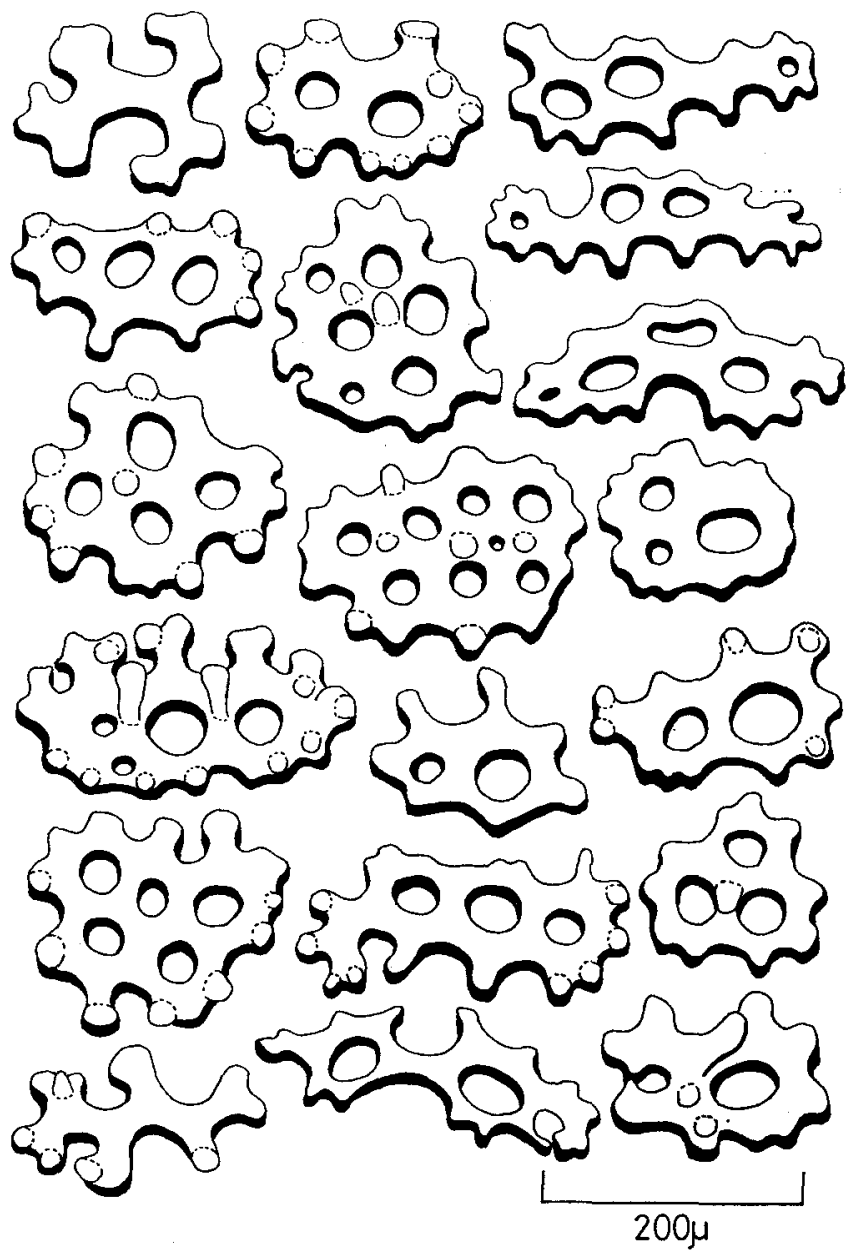

Fig. 6. Round and elongated plates from the marginal area of the ventral tegument of the smaller specimen. 
the larger one in each area. No clear difference is seen in diameter of holes and number of holes and protuberances in elongated ossicles between the two specimens. The above-mentioned features of ossicles in the ventral tegument may be summed up as follow: (1) round plates are furnished with more holes and protuberances in the larger specimen than in the smaller one and in the marginal area than in the central part in the smaller one, and (2) more round plates are furnished with protuberances in the larger specimen than in the smaller one and in the marginal area than in the central part in the smaller one. The ossicles around the mouth are represented by fenestrated plates and $70-240 \mu$ (the mean $161 \mu$ ) and $80-350 \mu$ or more in length in the smaller and larger specimens respectively. A few of them are furnished with some protuberances. The ossicles at each specimen are different. In the smaller specimen these ossicles resemble somewhat the ventral tegument (Fig. 8), while in

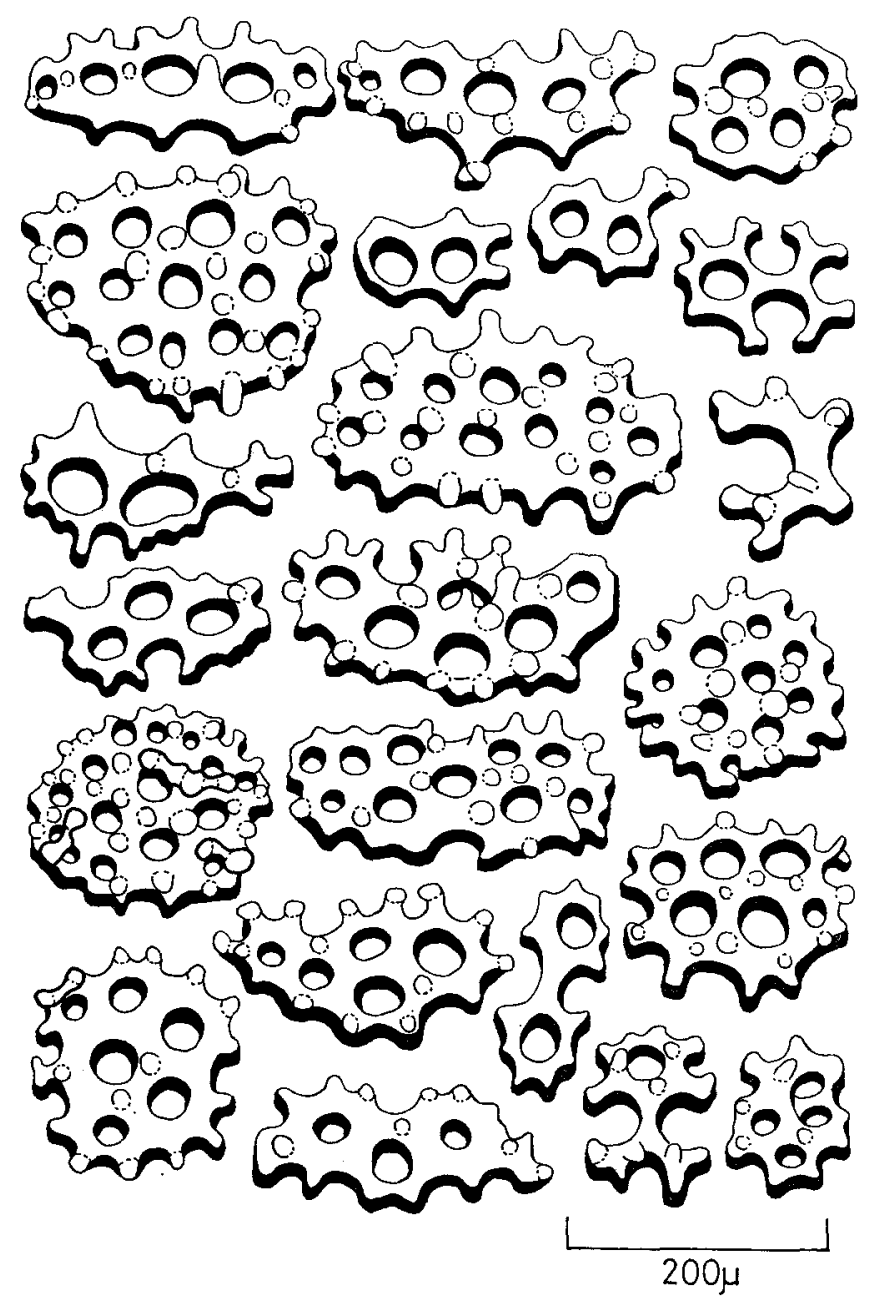

Fig. 7. Round and elongated plates from the marginal area of the ventral tegument of the larger specimen. 


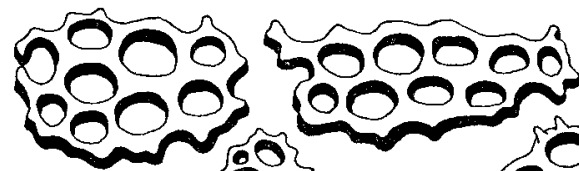

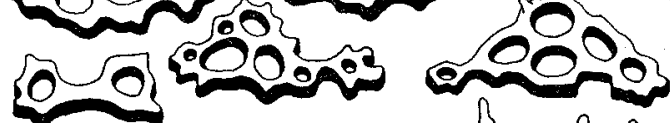

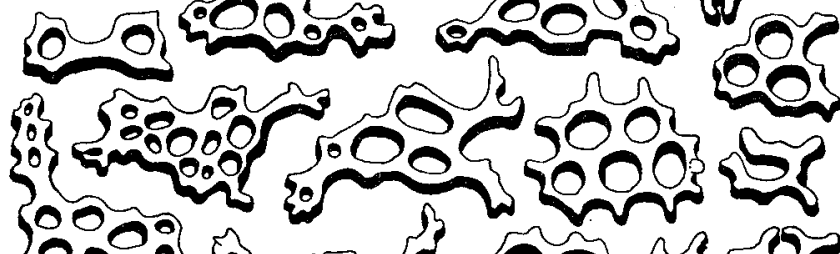

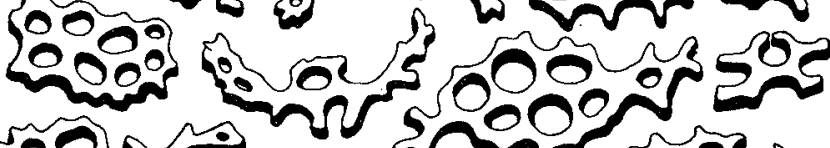

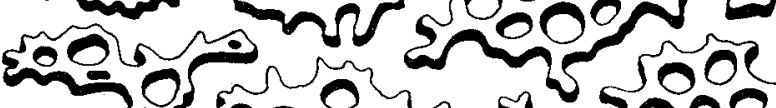

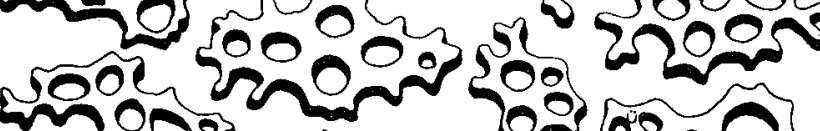

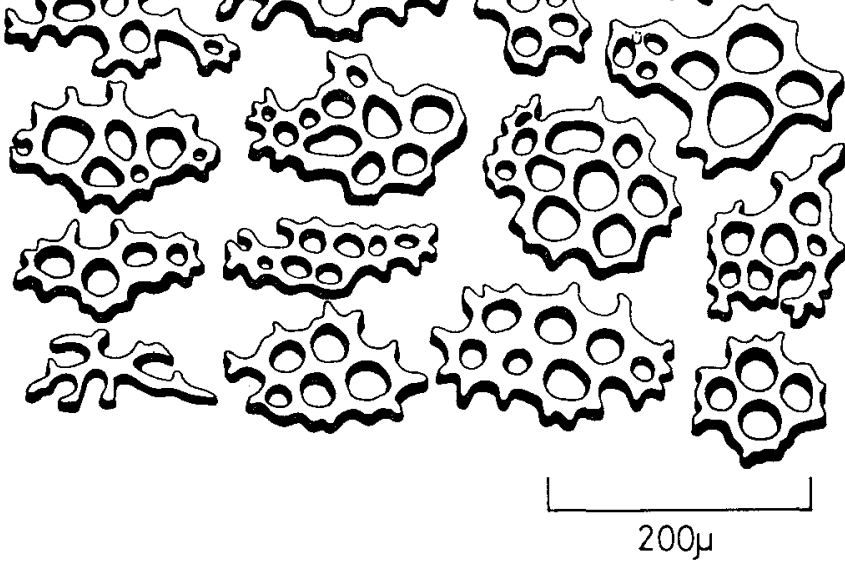

Fig. 8. Ossicles from around the mouth of the smaller specimen.

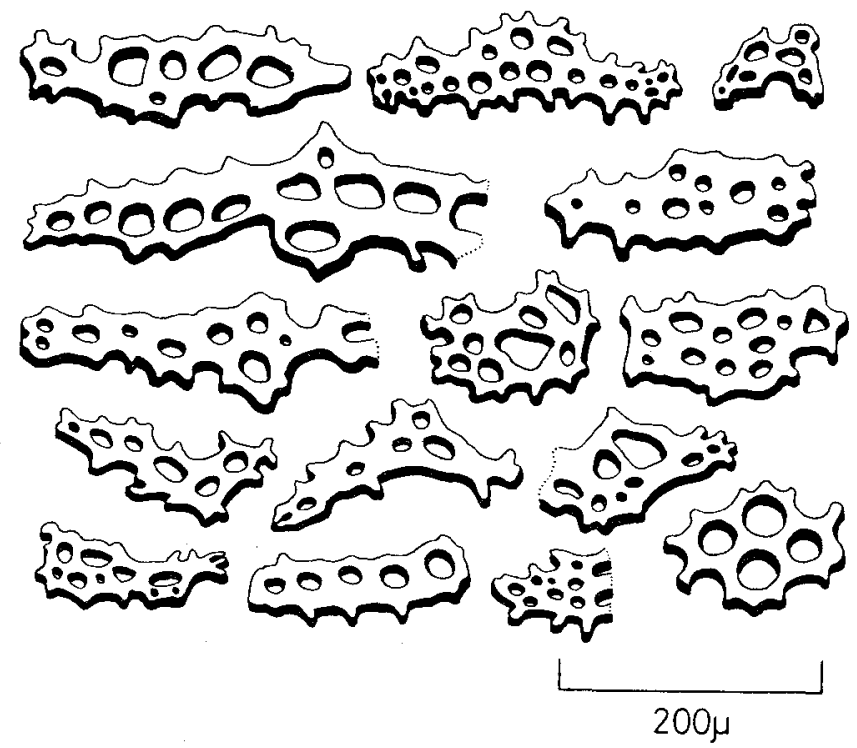

Fig. 9. Ossicles from around the mouth of the larger specimen. 
the larger specimen they somewhat resemble rather those from the tentacle (Fig. 9). Such a difference, however, might be only reflecting the difference between the sites from where the ossicles were obtained.

\section{Remarks}

The recorded localities of $P$. squamatus in the Japanese waters are the waters off Hokkaido (Ohshima, 1915 and 1918), Sagami Bay (Augustin, 1908 and Mitsukuri, 1912) and off Kii Peninsula (Utinomi, 1952) from the north to the south. The last may seemingly be the southern limit; the 67 specimens collected there are all much smaller, only $16-26 \mathrm{~mm}$ in length.

According to Ohsima's descriptions on the specimens from Hokkaido, the localities very near to that of the present specimen, only a few ossicles in the tube feet are provided with holes in his specimens. In the present specimens, however, the pseudobuttons with holes are much more abundant than the ossicles without holes in the tube feet. The ossicle from the tentacles shown in the text-figures by Oshima is about $280 \mu$ in length; probably this ossicle came from the distal part of the tentacle. In the specimens of Ohshima, the fenestrated plates in the ventral tegument are larger and furnished with protuberances more remarkably in the smaller specimens than in the larger ones. This is quite opposite to the case of the present specimens.

The larger of the present specimens is evidently of the higher and narrower type, but probably this is only reflecting the extent and the shape of the substratum and therefore of no use to judge whether the difference in size in the present specimens is reflecting the age or only some ecological conditions. Thus, at present, the gaps seen in the details of ossicles between the present observation and the Ohshima's cannot be explained properly. Probably, they may show a somewhat wide range of variations seen in the feature of ossicles in the northern form of $P$. squamatus.

Mitsukuri mentioned that in the specimens from Sagami Bay the dorsal scales were granulated but those around the mouth and the anus were not. In the present specimens, however, most of the oral and anal scales are granulated, while some of other dorsal scales are wholly devoid of granules. Though such granules on scales are easily turn off from the scale surface at handling, the granulation in scales may differ somewhat according to the age, populations, and localities.

According to Ekman's description (1932) treating the nothern (P. squamatus) and southern ( $P$. squamatus var. segregatus), the reduction of ossicles in the ventral tegumant is more progressed in the former than in the latter, and in the central part of the former the ossicles are strongly reduce or wholly missing. In the present larger specimen from the northern water, however, even the least sign of the reduction cannot be seen in the ossicles of the ventral tegument. According to Ekman, the projections along the periphery are more elongate in the northern type than in the southern type. In the present larger specimen, the projections are not elongate and rather resemble those in the southern type. In the southern type, the holes are larger in each ossicle in the central part than in the marginal area of the ventral 
tegument, and the peripheral projections of ossicles are never attenuated distally but ending rounded these distal swellings and the surface protuberances on ossicles may sometimes be knit together. In the present two specimens, the distal end of peripheral projections is rounded, and distal swellings and surface protuberances may join together as in the southern type. No clear difference in ossicle size is seen between the present two specimens. In the ossicles from the ventral tegument shown in the text-figures by Ekman, the holes of plates are larger in the northern type than in the southern type, and the holes of the round plates in the central part are larger than those of the elongated plates in the marginal area in each type. In the present specimens, the round plates are distributed in both the central part than in the marginal area in each specimen, and in the smaller specimen than in the larger one in each part.

According to Ekman the granules on scales are obtuse apically in the northern type, but swollen hemispherically in the southern type. In the present specimens, the granules are hemispherical and their size is intermediate between those of the northern and southern types.

Megascopically, the trend towards the differentiation between the northern and southern type described by Ekman may exist. The present specimens, however, show some characters of respective types. Evidently the present specimens from the northern waters resemble even the southern type as to certain features. Anyhow, it may be clear that the range of variations in the ossicles and the scale granules is surprisingly wide. At present, therefore, the author tends to support the opinion that $P$. squamatus var. segregatus is morphologically merged as a synonym of $P$. squamatus as Pawson (1969) did so in treating mainly the specimens of the southern type.

\section{REFERENCES}

Augustin, E. 1908. Uber japanishe Seewalzen. Ab. K. Bayer. Akad. Wiss., Math.-phys. KI. Suppl., 2(1): pp. 1-14, 2 pls.

Deichmann, E. 1941. The Holothurioidea collected by the "Velero III" during the years 19321938. Part I, Dendrochirota. Allan Hancock Pacific Exped., vol. 8, no. 3, pp. 61-194, pls. 10-30.

*_. 1947. Sallow wather holothurians from the cabo de Hornos and adjacent waters. An. Mus. argent. Cient. nat., vol. 42, pp. 325-351, figs. 1-5.

Ekamn, S. 1923. Uber Psolus squamatus und verwandte Arten. Ark. Zool., 15(5): pp. 1-59, 37 text-figs.

*_. 1925. Holothurien. Futher zool. Results Swed. Antarct. Exped., vol. 1, no. 6, pp. 1-194, figs.

* Koren, J. 1844. Beskrivelse over Tyone fusus og Cuvieria squamata. Nyt. Mag. Naturvid., vol. 14, pp. 203-205, pls. 1-3.

Mitsukuri, K. 1912. Studies on Actinopodus Holothurioidea. J. Coll. Sci. Tokyo Imp. Univ., vol. 29, no. 2, pp. 1-284, pls. 1-8.

Ohshima, H. 1915. Report on the holothurians collected by the United States Fisheries Steamer "Albatross" in the northwestern Pacific during the summer of 1906. Proc. U. S. natn. Mus., vol. 48, pp. 213-291, pls. 8-11.

1918. Report on the holothurians collected by the United States Fisheries Steamer "Albatross" in the northwestern Pacific during the summer of 1906. Zool. Mag. Tokyo, vol. 31, no 363, pp. 1-8. text-figs. 85-87. (In Japanese)

(* The author did not refer to this paper directly.) 
Pawson, D.L. 1969. Holothuroidea from Chili Report no. 46 of the Lund University Chili Expedition 1948-1949. Sarsia, vol. 38, pp. 121-145, 3 text-figs.

Utinomi, F. 1952. Echinoderms from off Minabe, Kii Peninsula, Japan. Record of animals collected by the trawlers Part 7. The Nanki Seibutsu Wakayama, vol. 4, no. 1-2, pp. 9-18. (In Japanese) 